\title{
Recent developments in predictive biomarkers of pediatric glioma (Review)
}

\author{
ZHENGWEI LI*, YIYU YIN* and FENGLI LIU \\ Department of Pediatric Surgery, Xuzhou Children's Hospital, Xuzhou, Jiangsu 221002, P.R. China
}

Received February 15, 2017; Accepted May 15, 2017

DOI: $10.3892 / \mathrm{ol} .2017 .6243$

\begin{abstract}
The presence of certain cancer-related genetic and epigenetic alterations in the tumor affects patient response to specific cancer therapies. The accurate screening of these predictive biomarkers in molecular diagnostics is important since it enables the tailoring of optimal treatment based on molecular characteristics of the tumor. We searched the electronic database PubMed for preclinical as well as clinical controlled trials reporting on various multiple predictors of glioma. It was observed clearly that multiple approaches are evolving and a few of them have also shown promising results. Depending on the type of gene alteration, a wide variety of methods may be applied in biomarker testing. Among the novel methods is next-generation sequencing (NGS) technology, enabling simultaneous detection of multiple alterations. The aim of this review is to discuss the predictive or potentially predictive genetic and epigenetic alterations of diffuse gliomas. The review concludes that NGS technology is the future and may likely replace, at least to some extent, the current routinely used methods, including FISH, IHC, and PCR-based methods, in clinical diagnostics.
\end{abstract}

\section{Contents}

1. Introduction

2. Histopathology and grading of gliomas

3. Predictive biomarkers in adult diffuse gliomas

4. Other potential therapeutic molecular targets in gliomas

5. Treatment of gliomas

6. Conclusions

Correspondence to: Dr Fengli Liu, Department of Pediatric Surgery, Xuzhou Children's Hospital, 18 Sudibei Road, Xuzhou, Jiangsu 221002, P.R. China

E-mail: ieswt61@163.com

*Contributed equally

Key words: gliomas, predictive markers, next-generation sequencing

\section{Introduction}

Tumors in the brain and central nervous system were estimated to account for $1.8 \%(256,000)$ of new cancer cases and $2.1 \%(142,000)$ of cancer deaths worldwide in $2012(1,2)$. This review focuses on gliomas, which arise from the supportive glial cells of the brain and account for approximately $30 \%$ of all central nervous system and brain tumors and $80 \%$ of malignant brain tumors (3). In addition to heritable risk variants, other factors with a proposed link to gliomas include, for example, ionizing radiation associated with increased risk and allergic conditions associated with reduced risk of gliomas (4). Additionally, some monogenic Mendelian syndromes, such as neurofibromatosis 1, Li-Fraumeni syndrome, tuberous sclerosis, and Lynch syndrome, predispose to gliomagenesis, but only a small proportion of all glioma cases is explained by these syndromes.

\section{Histopathology and grading of gliomas}

Based on cellular morphology, the World Health Organization (WHO) classification divides gliomas into three major subtypes: astrocytomas, oligodendrogliomas, and a mixture of these two cell types, oligoastrocytomas (5). Both oligondedrogliomas and oligoastrocytomas are also known as oligodendroglial tumors. The histological WHO grading system provides information on the biological aspects of the tumors, aiding prognosis and prediction of treatment response. WHO grade I tumors are benign, discrete, and curable by surgical removal, whereas WHO grade II-IV diffuse gliomas infiltrate into the surrounding brain tissue, thus preventing complete surgical removal and cure (6). Grade II tumors show increased cellularity, grade III tumors also show increased anaplasia and mitotic figures, and grade IV tumors show vascular proliferation and necrosis in addition to the aforementioned features. Grade IV astrocytoma, glioblastoma, is the most frequently occurring and most malignant glioma subtype. It is further subdivided into primary glioblastomas (95\% of cases), arising without evidence of pre-existing lower grade gliomas, and secondary glioblastomas (5\% of cases), developing from lower grade gliomas (7). Primary and secondary glioblastomas can not be distinguished by histopathology, but they exhibit genetic and epigenetic differences, and patients with secondary glioblastomas are typically younger at diagnosis (8). Certain molecular alterations are frequently seen in 
specific glioma subtypes and grades, and thus, they may further aid in the classification of tumors. Example of these alterations include codeletion of $1 \mathrm{p} / 19 \mathrm{q}$ in oligodendroglial tumors (9), IDH1 mutation in diffuse grade II-III gliomas and secondary glioblastomas (10), and loss of heterozygosity ( $\mathrm{LOH})$ of chromosome $10 \mathrm{q}$, EGFR amplification, TP53 mutations, p16 ${ }^{\mathrm{INK} 4 \mathrm{a}}$ (CDKN2A) deletions, and PTEN mutations in glioblastomas (7). In addition to contributing to the pathogenesis of gliomas, many of these molecular alterations have prognostic significance for prediction of the outcome of patients (11). For example, codeletion of $1 \mathrm{p} / 19 \mathrm{q}$ and $I D H 1$ mutations have been associated with favorable prognosis, whereas LOH 10q and PTEN mutations have been linked to poor prognosis.

Many factors, such as WHO grade, tumor location, age of the patient, performance status, and presence of specific molecular alterations, contribute to the outcome and treatment response of glioma patients. Population-based studies have shown the following 5-year survival rates (mean of the studies) for different glioma subtypes and grades: $68.5 \%$ in oligodendrogliomas (grade II), 50\% in oligoastrocytomas, $41.9 \%$ in astrocytomas (grade II), $34.4 \%$ in anaplastic oligodendrogliomas (grade III), $19.8 \%$ in anaplastic astrocytomas (grade III), and 3.4\% in glioblastomas (grade IV) [reviewed by Ostrom et al, 2014 (4)]. Despite the relatively good survival from slowly growing low-grade gliomas, they eventually progress to higher-grade gliomas (12).

\section{Predictive biomarkers in adult diffuse gliomas}

Codeletion of chromosomes $1 p$ and 19q. Combined loss of whole chromosome arms $1 \mathrm{p}$ and $19 \mathrm{q}$, potentially caused by an unbalanced translocation between the arms early in tumorigenesis (13), is a frequent change in oligodendroglial tumors, reported in 44-89\% of oligodendrogliomas (9) and in $19-38 \%$ of oligoastrocytomas (14). In astrocytomas/glioblastomas, the codeletion of $1 \mathrm{p} / 19 \mathrm{q}$ is a rare event. Although the tumor suppressor genes involved in the $1 p / 19 q$ loss have not been unequivocally identified, some candidate genes have been discovered within the lost chromosome arms, including genes coding for capicua transcriptional repressor (CIC) located at 19q13.2 and far upstream element (FUSE)-binding protein 1 (FUBP1) located at 1p31.1 (15). In patients diagnosed with anaplastic oligodendroglial tumors, the codeletion of $1 p / 19 q$ has been associated with better survival when the patients are treated with radiotherapy and combination chemotherapy of alkylating agents procarbazine and lomustine (CCNU) together with microtubule inhibitor vincristine (PCV) compared with radiotherapy alone (16). The predictive significance of codeleted $1 \mathrm{p} / 19 \mathrm{q}$ has also been indicated in low-grade gliomas, which show a good response to temozolomide chemotherapy (17). In addition to the predictive value of combined $1 \mathrm{p} / 19 \mathrm{q}$ loss, it also serves as a prognostic biomarker of a favorable prognosis (18).

$O^{6}$-methylguanine-DNA methyltransferase (MGMT) promoter hypermethylation. MGMT is a DNA repair enzyme that functions in the removal of alkyl groups from $\mathrm{O}^{6}$ position of guanine caused by DNA-alkylating agents such as temozolomide. Hypermethylation of the promoter region of the MGMT gene located at 10q26 leads to reduced
MGMT expression and DNA repair activity, affecting the sensitivity of $M G M T$-methylated gliomas to alkylating agents (19). MGMT hypermethylation has been associated with improved survival in glioblastomas treated with combined temozolomide and radiotherapy compared with radiotherapy alone (20). In a study by Hegi et al (21), the median OS was 21.7 months (95\% CI, 17.4-20.4 months) for MGMT-methylated glioblastoma patients treated with temozolomide plus radiotherapy compared with 15.3 months for patients treated with radiotherapy $(\mathrm{p}=0.007)$. For patients with unmethylated $M G M T$, the median OS was very similar regardless of the treatment received. Furthermore, among MGMT-methylated glioblastoma patients, the median progression-free survival (PFS) was 10.3 months (6.5-14.0) for temozolomide plus radiotherapy and 5.9 months (5.3-7.7) for radiotherapy alone $(\mathrm{p}=0.001)$, and among patients with unmethylated $M G M T, 5.3$ months (5.0-7.6) for temozolomide plus radiotherapy and 4.4 months (3.1-6.0) for radiotherapy alone $(\mathrm{p}=0.02)$. Recently, temozolomide treatment was compared with radiotherapy in elderly (>65-70 years) glioblastoma patients with and without MGMT hypermethylation (22). These studies suggested that $M G M T$ hypermethylation predicts a favorable response to temozolomide treatment in elderly glioblastoma patients, whereas unmethylated $M G M T$ seemed to predict lack of survival benefit from alkylating agent chemotherapy. For example, Wick et al (22) showed that the glioblastoma patients with $M G M T$ hypermethylation had longer event-free survival when treated with temozolomide than patients treated with radiotherapy. On the other hand, the patients with unmethylated MGMT who received temozolomide showed shorter survival than those who underwent radiotherapy. Resistance to temozolomide often emerges also in patients with hypermethylated $M G M T$ promoter and a good primary response to temozolomide. Although the underlying mechanism for this resistance is not yet established, increased $M G M T$ activity and DNA mismatch repair deficiency have been suggested (23).

Hypermethylation of the $M G M T$ promoter has been reported to occur in approximately $50 \%$ of astrocytomas (including glioblastomas) and in approximately $70 \%$ of oligodendroglial tumors (24). Studies in recent past have shown the value of $M G M T$ hypermethylation in the prediction of favorable prognosis in various glioma subtypes $(25,26)$. The $M G M T$ methylation status has also been suggested to be useful in distinguishing pseudoprogression from real progression of cancer, as MGMT hypermethylation is significantly associated with pseudoprogression (27). Moreover, the presence of $M G M T$ hypermethylation is significantly associated with IDH1 mutation and $1 \mathrm{p} / 19 \mathrm{q}$ codeletion (28). Interestingly, a recent report showed that the assessment of both $M G M T$ methylation and IDHI mutation status in glioblastoma patients provides a better prediction of survival than either status alone (29). The longest survival was observed in patients carrying $M G M T$ methylation and $I D H 1$ mutation, whereas patients with unmethylated $M G M T$ and unmutated IDH1 had the shortest survival. Furthermore, IDHI mutation status is suggested to affect how MGMT-methylated high-grade gliomas benefit from alkylating agent chemotherapy, since $M G M T$ hypermethylation is associated with 
a better survival in $I D H 1$-negative but not $I D H 1$-positive patients treated with chemotherapy (30).

IDH1 mutations. IDH1 gene located at chromosome 2q33.3 codes for cytocolic isocitrate dehydrogenase $1\left(\mathrm{NADP}^{+}\right)$ enzyme involved in the citric acid cycle. IDH1 mutations are early alterations in gliomagenesis, suggested to occur before TP53 mutations and codeletion of $1 \mathrm{p} / 19 \mathrm{q}$ (31). The mutations in IDH1 are detected in $64-100 \%$ of diffuse grade II-III gliomas, and secondary glioblastomas, but only in 5-7\% of primary glioblastomas (32). The majority of mutations in IDH1 affect the arginine amino acid at codon 132, which is substituted with histidine $(\mathrm{R} 132 \mathrm{H})$ in the most common type of mutations. Mutations in IDH2 gene (at 15q26.1) encoding the mitochondrial isocitrate dehydrogenase 2 $\left(\mathrm{NADP}^{+}\right)$enzyme are also observed in gliomas, but at a lower frequency (approximately 3\%) (32). IDH1 and 2 enzymes catalyze the conversion of isocitrate to $\alpha$-ketoglutarate, but when mutated, they begin to produce the oncometabolite 2-hydroxyglutarate, the accumulation of which is suggested to eventually lead to cancer-promoting alterations such as genome-wide histone and DNA methylation changes $(33,34)$. The predictive value of $I D H 1 / 2$ mutations remains to be clarified; some studies have reported no impact of $I D H I$ mutations on response to temozolomide in low-grade astrocytomas (35) or PCV chemotherapy in anaplastic oligodendrogliomas (26), whereas others have shown an improved response to temozolomide chemotherapy in $I D H$-mutant low-grade gliomas (36) and secondary glioblastomas (37) or a benefit from PCV chemotherapy in anaplastic oligodendroglial tumors (38). Recently, promising results have been obtained by a selective R132H-IDH1 inhibitor, which appears to impair growth and promote differentiation of glioma cells harboring the $I D H 1$ mutation (39). IDH-mutated gliomas have been associated with a favorable prognosis in numerous studies (40).

\section{Other potential therapeutic molecular targets in gliomas}

Several clinical studies of novel therapeutic agents targeting single or multiple molecular alterations of gliomas have been performed in recent years and many studies are ongoing (41). Examples of investigated therapeutic molecular targets include cell surface molecular receptors and their ligands, such as EGFR, VEGF, VEGFR, PDGFR, and integrins, downstream signaling effectors, such as Ras, MAPK (ERK), mTOR, and protein kinase C, and other molecular targets, such as histone deacetylases and proteasome. Many of these molecular targets show increased expression or activation in gliomas. Despite the large number of studies performed on potential therapeutic agents (e.g., inhibitors), none has shown significant improvement in the survival of glioma patients.

\section{Treatment of gliomas}

The standard treatment options for newly diagnosed gliomas include surgical resection (or a biopsy if surgery cannot be performed), radiotherapy, and chemotherapy. Treatment for low-grade (grade II) diffuse gliomas consists of a resection, possibly followed by radiotherapy or chemotherapy (42).
Options for treatment of anaplastic (grade III) gliomas include surgical resection, followed by radiotherapy and/or chemotherapy, whereas standard care for patients $(<65-70$ years) with glioblastomas (grade IV) combines resection, radiotherapy, and chemotherapy with the alkylating agent temozolomide (43). Anaplastic oligodendroglial tumors harboring 1p/19q codeletion and elderly ( $>65-70$ years) patients with glioblastomas harboring $M G M T$ promoter hypermethylation can be treated by surgery and chemotherapy with or without radiotherapy (43). The blood-brain barrier complicates the treatment of gliomas since many chemotherapeutic drugs cannot be delivered to the central nervous system across the barrier, and even with a successful delivery, the concentration of the drug in the brain might be low (44).

\section{Conclusions}

It is concluded that next-generation sequencing (NGS) technology is the future and is likely to replace, at least to some extent, the current routinely used methods, including FISH, IHC, and PCR-based methods, in clinical diagnostics. The great benefit of targeted NGS over the other available methods is the possibility to simultaneously screen all known predictive biomarkers. NGS also has applications for analysis of methylation and gene expression. Collectively, NGS enables the assessment of a more complete picture of the molecular architecture of tumors, which could lead to more efficient treatment decisions.

\section{References}

1. Ferlay J, Soerjomataram I, Dikshit R, Eser S, Mathers C, Rebelo M, Parkin DM, Forman D and Bray F: Cancer incidence and mortality worldwide: Sources, methods and major patterns in GLOBOCAN 2012. Int J Cancer 136: E359-E386, 2015.

2. Nakajima R, Abe K, Momose M, Fukushima K, Matsuo Y, Kimura K, Kondo C and Sakai S: Optimization of scan initiation timing after (11)C-methionine administration for the diagnosis of suspected recurrent brain tumors. Ann Nucl Med 31: 190-197, 2017.

3. Goodenberger ML and Jenkins RB: Genetics of adult glioma. Cancer Genet 205: 613-621, 2012.

4. Ostrom QT, Bauchet L, Davis FG, Deltour I, Fisher JL, Langer CE, Pekmezci M, Schwartzbaum JA, Turner MC, Walsh KM, et al: The epidemiology of glioma in adults: A 'state of the science' review. Neuro Oncol 16: 896-913, 2014.

5. Louis DN, Ohgaki H, Wiestler OD, Cavenee WK, Burger PC, Jouvet A, Scheithauer BW and Kleihues P: The 2007 WHO classification of tumours of the central nervous system. Acta Neuropathol 114: 97-109, 2007b.

6. Claes A, Idema AJ and Wesseling P: Diffuse glioma growth: A guerilla war. Acta Neuropathol 114: 443-458, 2007.

7. Ohgaki H, Dessen P, Jourde B, Horstmann S, Nishikawa T, Di Patre PL, Burkhard C, Schüler D, Probst-Hensch NM, Maiorka PC, et al: Genetic pathways to glioblastoma: A population-based study. Cancer Res 64: 6892-6899, 2004.

8. Ohgaki $\mathrm{H}$ and Kleihues P: Genetic pathways to primary and secondary glioblastoma. Am J Pathol 170: 1445-1453, 2007.

9. Jeuken JW, Sijben A, Bleeker FE, Boots-Sprenger SH, Rijntjes J, Gijtenbeek JM, Mueller W and Wesseling P: The nature and timing of specific copy number changes in the course of molecular progression in diffuse gliomas: Further elucidation of their genetic 'life story'. Brain Pathol 21: 308-320, 2011.

10. Yan H, Parsons DW, Jin G, McLendon R, Rasheed BA, Yuan W, Kos I, Batinic-Haberle I, Jones S, Riggins GJ, et al: IDH1 and IDH2 mutations in gliomas. N Engl J Med 360: 765-773, 2009.

11. Haynes HR, Camelo-Piragua S and Kurian KM: Prognostic and predictive biomarkers in adult and pediatric gliomas: Toward personalized treatment. Front Oncol 4: 47, 2014. 
12. Riemenschneider MJ, Jeuken JW, Wesseling $P$ and Reifenberger G: Molecular diagnostics of gliomas: State of the art. Acta Neuropathol 120: 567-584, 2010.

13. Jenkins RB, Blair H, Ballman KV, Giannini C, Arusell RM, Law M, Flynn H, Passe S, Felten S, Brown PD, et al: A t $(1 ; 19)$ (q10;p10) mediates the combined deletions of $1 p$ and $19 q$ and predicts a better prognosis of patients with oligodendroglioma. Cancer Res 66: 9852-9861, 2006.

14. Miller CR,Dunham CP,Scheithauer BW and Perry A: Significance of necrosis in grading of oligodendroglial neoplasms: A clinicopathologic and genetic study of newly diagnosed high-grade gliomas. J Clin Oncol 24: 5419-5426, 2006.

15. Bettegowda C, Agrawal N, Jiao Y, Sausen M, Wood LD, Hruban RH, Rodriguez FJ, Cahill DP, McLendon R, Riggins G, et al: Mutations in CIC and FUBP1 contribute to human oligodendroglioma. Science 333: 1453-1455, 2011.

16. Cairncross G, Wang M, Shaw E, Jenkins R, Brachman D, Buckner J, Fink K, Souhami L, Laperriere N, Curran W, et al: Phase III trial of chemoradiotherapy for anaplastic oligodendroglioma: Long-term results of RTOG 9402. J Clin Oncol 31: 337-343, 2013.

17. Kaloshi G, Benouaich-Amiel A, Diakite F, Taillibert S, Lejeune J, Laigle-Donadey F, Renard MA, Iraqi W, Idbaih A, Paris S, et al: Temozolomide for low-grade gliomas: Predictive impact of $1 \mathrm{p} / 19 \mathrm{q}$ loss on response and outcome. Neurology 68 : 1831-1836, 2007.

18. Aldape K, Burger PC and Perry A: Clinicopathologic aspects of $1 \mathrm{p} / 19 \mathrm{q}$ loss and the diagnosis of oligodendroglioma. Arch Pathol Lab Med 131: 242-251, 2007.

19. Esteller M, Garcia-Foncillas J, Andion E, Goodman SN, Hidalgo OF, Vanaclocha V, Baylin SB and Herman JG: Inactivation of the DNA-repair gene MGMT and the clinical response of gliomas to alkylating agents. N Engl J Med 343 1350-1354, 2000.

20. Weller M, Felsberg J, Hartmann C, Berger H, Steinbach JP Schramm J, Westphal M, Schackert G, Simon M, Tonn JC, et al: Molecular predictors of progression-free and overall survival in patients with newly diagnosed glioblastoma: A prospective translational study of the German Glioma Network. J Clin Oncol 27: 5743-5750, 2009.

21. Hegi ME, Diserens AC, Gorlia T, Hamou MF, de Tribolet N, Weller M, Kros JM, Hainfellner JA, Mason W, Mariani L, et al: MGMT gene silencing and benefit from temozolomide in glioblastoma. N Engl J Med 352: 997-1003, 2005.

22. Wick W, Platten M, Meisner C, Felsberg J, Tabatabai G, Simon M, Nikkhah G, Papsdorf K, Steinbach JP, Sabel M, et al; NOA-08 Study Group of Neuro-oncology Working Group (NOA) of German Cancer Society: Temozolomide chemotherapy alone versus radiotherapy alone for malignant astrocytoma in the elderly: The NOA-08 randomised, phase 3 trial. Lancet Oncol 13: 707-715, 2012.

23. Zhang J, Stevens MF and Bradshaw TD: Temozolomide: Mechanisms of action, repair and resistance. Curr Mol Pharmacol 5: 102-114, 2012.

24. Weller M, Stupp R, Reifenberger G, Brandes AA, van den Bent MJ, Wick W and Hegi ME: MGMT promoter methylation in malignant gliomas: Ready for personalized medicine? Nat Rev Neurol 6: 39-51, 2010.

25. Olson RA, Brastianos PK and Palma DA: Prognostic and predictive value of epigenetic silencing of MGMT in patients with high grade gliomas: A systematic review and meta-analysis. J Neurooncol 105: 325-335, 2011.

26. van den Bent MJ, Dubbink HJ, Sanson M, van der LeeHaarloo CR, Hegi M, Jeuken JW, Ibdaih A, Brandes AA, Taphoorn MJ, Frenay M, et al: MGMT promoter methylation is prognostic but not predictive for outcome to adjuvant PCV chemotherapy in anaplastic oligodendroglial tumors: A report from EORTC Brain Tumor Group Study 26951. J Clin Oncol 27 5881-5886, 2009.

27. Brandes AA, Franceschi E, Tosoni A, Blatt V, Pession A, Tallini G, Bertorelle R, Bartolini S, Calbucci F, Andreoli A, et al: MGMT promoter methylation status can predict the incidence and outcome of pseudoprogression after concomitant radiochemotherapy in newly diagnosed glioblastoma patients. J Clin Oncol 26: 2192-2197, 2008.
28. Mellai M, Piazzi A, Caldera V, Monzeglio O, Cassoni P, Valente $\mathrm{G}$ and Schiffer D: IDH1 and IDH2 mutations, immunohistochemistry and associations in a series of brain tumors. $\mathrm{J}$ Neurooncol 105: 345-357, 2011.

29. Molenaar RJ, Verbaan D, Lamba S, Zanon C, Jeuken JW, Boots-Sprenger SH, Wesseling P, Hulsebos TJ, Troost D, van Tilborg AA, et al: The combination of IDH1 mutations and MGMT methylation status predicts survival in glioblastoma better than either IDH1 or MGMT alone. Neuro-oncol 16: 1263-1273, 2014.

30. Wick W, Meisner C, Hentschel B, Platten M, Schilling A, Wiestler B, Sabel MC, Koeppen S, Ketter R, Weiler M, et al: Prognostic or predictive value of MGMT promoter methylation in gliomas depends on IDH1 mutation. Neurology 81: 1515-1522, 2013.

31. Watanabe T, Nobusawa S, Kleihues P and Ohgaki H: IDH1 mutations are early events in the development of astrocytomas and oligodendrogliomas. Am J Pathol 174: 1149-1153, 2009.

32. Hartmann C, Meyer J, Balss J, Capper D, Mueller W, Christians A, Felsberg J, Wolter M, Mawrin C, Wick W, et al: Type and frequency of IDH1 and IDH2 mutations are related to astrocytic and oligodendroglial differentiation and age: A study of 1,010 diffuse gliomas. Acta Neuropathol 118: 469-474, 2009.

33. Turcan S, Rohle D, Goenka A, Walsh LA, Fang F, Yilmaz E, Campos C, Fabius AW, Lu C, Ward PS, et al: IDH1 mutation is sufficient to establish the glioma hypermethylator phenotype. Nature 483: 479-483, 2012.

34. Lu C, Ward PS, Kapoor GS, Rohle D, Turcan S, Abdel-Wahab O, Edwards CR, Khanin R, Figueroa ME, Melnick A, et al: IDH mutation impairs histone demethylation and results in a block to cell differentiation. Nature 483: 474-478, 2012.

35. Dubbink HJ, Taal W, van Marion R, Kros JM, van Heuvel I, Bromberg JE, Zonnenberg BA, Zonnenberg CB, Postma TJ, Gijtenbeek JM, et al: IDH1 mutations in low-grade astrocytomas predict survival but not response to temozolomide. Neurology 73 : 1792-1795, 2009.

36. Houillier C, Wang X, Kaloshi G, Mokhtari K, Guillevin R, Laffaire J, Paris S, Boisselier B, Idbaih A, Laigle-Donadey F, et al: IDH1 or IDH2 mutations predict longer survival and response to temozolomide in low-grade gliomas. Neurology 75 : 1560-1566, 2010.

37. SongTao Q, Lei Y, Si G, YanQing D, HuiXia H, XueLin Z, LanXiao W and Fei Y: IDH mutations predict longer survival and response to temozolomide in secondary glioblastoma. Cancer Sci 103: 269-273, 2012

38. Cairncross JG, Wang M, Jenkins RB, Shaw EG, Giannini C, Brachman DG, Buckner JC, Fink KL, Souhami L, Laperriere NJ, et al: Benefit from procarbazine, lomustine, and vincristine in oligodendroglial tumors is associated with mutation of IDH. J Clin Oncol 32: 783-790, 2014.

39. Rohle D, Popovici-Muller J, Palaskas N, Turcan S, Grommes C, Campos C, Tsoi J, Clark O, Oldrini B, Komisopoulou E, et al: An inhibitor of mutant IDH1 delays growth and promotes differentiation of glioma cells. Science 340: 626-630, 2013.

40. Zou P, Xu H, Chen P, Yan Q, Zhao L, Zhao P and Gu A: IDH1/IDH2 mutations define the prognosis and molecular profiles of patients with gliomas: A meta-analysis. PLoS One 8: e68782, 2013.

41. Hamza MA and Gilbert M: Targeted therapy in gliomas. Curr Oncol Rep 16: 379, 2014.

42. Tandon A and Schiff D: Therapeutic decision making in patients with newly diagnosed low grade glioma. Curr Treat Options Oncol 15: 529-538, 2014.

43. Weller M, van den Bent M, Hopkins K, Tonn JC, Stupp R, Falini A, Cohen-Jonathan-Moyal E, Frappaz D, Henriksson R, Balana C, et al; European Association for Neuro-Oncology (EANO) Task Force on Malignant Glioma: EANO guideline for the diagnosis and treatment of anaplastic gliomas and glioblastoma. Lancet Oncol 15: e395-e403, 2014.

44. Muldoon LL, Soussain C, Jahnke K, Johanson C, Siegal T, Smith QR, Hall WA, Hynynen K, Senter PD, Peereboom DM, et al: Chemotherapy delivery issues in central nervous system malignancy: A reality check. J Clin Oncol 25: 2295-2305, 2007. 